\title{
Population level impact of a pulse oximetry remote monitoring programme on mortality and healthcare utilisation in the people with covid-19 in England: a national analysis using a stepped wedge design
}

Beaney $\mathrm{T}^{1,2}$ (0000-0001-9709-7264), Clarke $\mathrm{J}^{1,3}$, Alboksmaty $\mathrm{A}^{1,2}$, Flott $\mathrm{K}^{1}$, Fowler $\mathrm{A}^{4}$, Benger $\mathrm{JR}^{5}$, Aylin $\mathrm{P}^{1,2}$, Elkin $\mathrm{S}^{6}$, Neves $\mathrm{AL}^{1}$, Darzi $\mathrm{A}^{1}$

1. Patient Safety Translational Research Centre, Institute of Global Health Innovation, Imperial College London, London, SW7 2AZ, United Kingdom

2. Department of Primary Care and Public Health, Imperial College London, London, W6 8RP, United Kingdom

3. Centre for Mathematics of Precision Healthcare, Department of Mathematics, Imperial College London, London, SW7 2AZ, United Kingdom

4. NHS England and Improvement, London, SE1 6LH, United Kingdom

5. NHS Digital, 7-8 Wellington Place, Leeds, West Yorkshire, LS1 4AP, United Kingdom

6. National Heart and Lung Institute, Imperial College London, London, SW7 2AZ United Kingdom

Word count: 3233

Corresponding Author:

Dr Thomas Beaney

Patient Safety Translational Research Centre, Institute of Global Health Innovation, Imperial

College London, London, SW7 2AZ, United Kingdom

Email: thomas.beaney@imperial.ac.uk 


\begin{abstract}

\section{Objectives}

To identify the population level impact of a national pulse oximetry remote monitoring programme for covid-19 (COVID Oximetry @ home; CO@h) in England on mortality and health service use.
\end{abstract}

\title{
Design
}

Retrospective cohort study using a stepped wedge pre- and post- implementation design.

\section{Setting}

All Clinical Commissioning Groups (CCGs) in England implementing a local CO@ h programme.

\section{Participants}

217,650 people with a positive covid-19 polymerase chain reaction test result and symptomatic, from $1^{\text {st }}$ October 2020 to $3^{\text {rd }}$ May 2021, aged $\geq 65$ years or identified as clinically extremely vulnerable. Care home residents were excluded.

\section{Interventions}

A pre-intervention period before implementation of the CO@ h programme in each CCG was compared to a post-intervention period after implementation.

\section{Main outcome measures}

Five outcome measures within 28 days of a positive covid-19 test: i) death from any cause; ii) any $A \& E$ attendance; iii) any emergency hospital admission; iv) critical care admission; and v) total length of hospital stay.

\section{Results}

Implementation of the programme was not associated with mortality or length of hospital stay. Implementation was associated with increased health service utilisation with a $12 \%$ increase in the odds of A\&E attendance (95\% CI: 6\%-18\%) and emergency hospital admission (95\% CI: 5\%-20\%) and a 24\% increase in the odds of critical care admission in those admitted (95\% CI: 5\%-47\%). In a secondary analysis of CO@ h sites with at least 10\% or $20 \%$ of eligible people enrolled, there was no significant association with any outcome measure. However, uptake of the programme was low, with enrolment data received for only $5,527(2.5 \%)$ of the eligible population.

\section{Conclusions}

At a population level, there was no association with mortality following implementation of the $\mathrm{CO} @ \mathrm{~h}$ programme, and small increases in health service utilisation were observed. Low 
medRxiv preprint doi: https://doi.org/10.1101/2021.11.29.21266847; this version posted November 30, 2021. The copyright holder for this preprint (which was not certified by peer review) is the author/funder, who has granted medRxiv a license to display the preprint in perpetuity. It is made available under a CC-BY 4.0 International license .

enrolment of eligible people may have diluted the effects of the programme at a population level. 


\section{Background}

Since the start of the covid-19 pandemic, asymptomatic ('silent') hypoxia has complicated the assessment and care of patients with covid-19.[1] Hypoxia has been shown to be an important predictor of mortality and the need for hospital admission in patients with covid19 , yet those patients with asymptomatic hypoxia may be unaware of dangerously low blood oxygen saturations.[2,3] Pulse oximetry allows patients and clinicians to regularly monitor a patient's oxygen saturation and promptly initiate escalation of treatment should deterioration occur.[1] Health systems across the world introduced remote monitoring pathways, including the use of pulse oximetry, to support the care of patients with Covid-19 outside hospital.[4,5] In November 2020, NHS England and Improvement (NHSEI) introduced the COVID Oximetry@home (CO@h) programme, recommending that all Clinical Commissioning Groups (CCGs) in England provide services to monitor patients with a diagnosis of covid-19 at home using pulse oximetry.[6] This service builds upon local remote monitoring services provided by individual CCGs in earlier stages of the pandemic. CCGs are responsible for the establishment of services in their area, although CO@ h services may be shared between CCGs, and more than one service may operate within a single CCG.[7]

Patients are eligible for enrolment into a CO@h programme if they have symptomatic covid19 and are aged 65 years or older or are identified as clinically extremely vulnerable (CEV) based on concurrent medical conditions and/or treatments.[8] Additionally, clinical judgement can be applied to consider other individual risk factors, including pregnancy, learning disability, and socioeconomic deprivation. Those enrolled are encouraged to record three oximetry readings daily and advised to attend or call emergency services if the reading is $92 \%$ or less, or to contact primary care services for readings of $93-94 \%$. The programme is intended to accept patients from primary care, NHS Test and Trace, ambulance services and accident and emergency departments, in contrast to 'COVID Virtual Wards' which aim to support discharge of covid-19 patients from hospital.[9]

The clinical effectiveness of the CO@ h programme on mortality and secondary care utilisation remains unknown. The primary aim of this analysis is to identify the impact of the $\mathrm{CO} @ \mathrm{~h}$ programme on mortality and use of healthcare services at a population level amongst people eligible for the programme. A secondary aim is to identify the impact of the programme in sites with a high uptake of the programme amongst the eligible population. 


\section{Methods}

This study used a retrospective cohort of people eligible for the CO@ $\mathrm{h}$ programme, comparing outcomes at a CCG level using a stepped wedge pre- and post-implementation design. Eligibility was defined as the population resident in England, with a positive covid-19 Polymerase Chain Reaction (PCR) test result, who were symptomatic at the time of testing, from $1^{\text {st }}$ October 2020 to $3^{\text {rd }}$ May 2021. Of these individuals, a subset of people who would have remained eligible throughout the course of the programme, aged 65 years or older, or who were Clinically Extremely Vulnerable (CEV) was selected. Care home residents were excluded from the analysis, as previous work has suggested significantly higher mortality in this group.[10]

Five primary outcomes were selected, defined as occurring within 28 days of the date of a positive covid-19 test:

1. Death from any cause

2. One or more Accident and Emergency department (A\&E) attendances

3. One or more emergency hospital admissions

4. One or more critical care admissions (of those admitted to hospital)

5. Total hospital length of stay in days, of those admitted who did not die within 28 days

\section{Data sources and processing}

Covid-19 testing data was provided through the Public Health England Second Generation Surveillance System[11], which collates positive covid-19 test results conducted in laboratories across England. Data was available from $1^{\text {st }}$ October 2020 to $3^{\text {rd }}$ May 2021. This analysis used PCR tests, with symptoms documented at the time of testing.[12] Where more than one test was recorded, only the date of first test was used. Data on the number of patients enrolled ('onboarded') onto the $\mathrm{CO} @ \mathrm{~h}$ programme were submitted from $\mathrm{CO} @ \mathrm{~h}$ sites via NHS Digital's Strategic Data Collection Service (SDCS).[13] Primary care data was sourced from the General Practice Extraction Service (GPES) Data for Pandemic Planning and Research (GDPPR).[14] Hospital Episode Statistics (HES) data[15] and the Emergency Care Data Set[16] provided data on hospital admissions and A\&E attendances up to $31^{\text {st }}$ May 2021. Data on registration of deaths was sourced from the Office for National Statistics (ONS), with data available up to $5^{\text {th }}$ July 2021. Datasets were linked using a deidentified NHS patient ID. 
The study population were assigned to a CCG based on a person's CCG of residence when the test was performed. Patient demographic data, including age, sex, ethnicity, lower layer super output area (LSOA) of residence were derived from GDPPR, or, if missing, derived from HES or ECDS. LSOA was linked to measures of deprivation based on the Index of Multiple Deprivation (IMD) 2019.[17] Data on care home residence, CEV status, body mass index (BMI) and smoking status were available from GDPPR only. Information on the following chronic conditions were included, derived from GDPPR: hypertension, chronic cardiac disease, chronic kidney disease, chronic respiratory disease, dementia, diabetes, chronic neurological disease (including epilepsy), learning disability, malignancy/immunosuppression, severe mental illness, peripheral vascular disease and stroke/transient ischaemic attack (TIA). For demographics and chronic conditions, the most recent codes prior to the date of a positive covid-19 test were used to exclude those which may have resulted from covid-19 infection. If no data were available prior to the date of a positive test for age, sex and ethnicity only, then the earliest data following the positive test was used. Full details of the datasets and cleaning approach are provided in Appendix A, with a link to the Systematized Nomenclature of Medicine Clinical Terms (SNOMED-CT) codes for each condition in appendix A.

\section{Statistical analysis}

A pre- and post-implementation period were defined for each $\mathrm{CO} @ \mathrm{~h}$ site, with implementation start dates for each site provided by NHS England @ home. A stepped wedge design was used. All eligible people in each CCG before and after implementation of the $\mathrm{CO} @ \mathrm{~h}$ programme were allocated to the control group and intervention group, respectively. Two-level hierarchical regression models were run for each outcome, incorporating random intercepts for CCG. Logistic regression was used for the four binary endpoints and negative binomial regression models were used for the single continuous outcome (length of stay). Total length of stay was capped at 28 days where a patient was discharged after the 28-day window, and analyses of length of stay excluded patients who died within the 28-day time window.

To account for possible changes in the baseline risk of each outcome over time, the primary models for each outcome incorporated fixed effects for the month of positive covid-19 test. To account for potential differences in the at-risk population before and after implementation, the primary models adjusted patient-level risk factors. Final covariates in each model 
included age category (years), sex, ethnicity, IMD score, BMI category, month of covid-19 test, CEV status, and clinical co-morbidities. Intra-class correlation coefficients were calculated for each model.

To test the sensitivity of results to time-varying effects and differences in patient risk factors, a series of sensitivity analyses were run:

1. A naïve model, not accounting for time or patient-level covariates

2. A time-adjusted model, without adjusting for patient-level covariates

3. A time-adjusted model, incorporating a random interaction between time and CCG

4. A time-adjusted model incorporating a random interaction between time and CCG, and adjusting for patient-level covariates

A secondary analysis was performed on the subset of sites with a higher proportion of eligible people enrolled. Two thresholds were defined a priori, at 10\% or more (accounting for sixteen CCGs and $9.4 \%$ of the eligible population) and $20 \%$ more (accounting for five CCGs and $2.4 \%$ of the eligible population) across the whole study period.

Analyses were conducted in the Big Data and Analytics Unit Secure Environment (BDAU SE), Imperial College. Python v3.9.5 and Pandas v1.2.3 were used in data manipulation. Regression models were conducted in Stata v17.0, using the melogit and menbreg commands.

\section{Patient and public involvement}

Patients or the public were not involved in the design, conduct or reporting of our research.

\section{Results}

A total of 1,714,182 people resident in 106 CCGs in England had a positive PCR covid-19 test between 1 October 2020 and 3rd May 2021, with documented symptoms at the time of the test. Eligibility for the $\mathrm{CO} @ \mathrm{~h}$ programme was defined as a person being at least 65 years of age or CEV, resulting in an eligible population of 223,429 (13.0\%). Of these, 5,779 (2.6\%) were living in a care home at the time of their positive test and were excluded from the analysis. A total of 217,650 people were included in the final analysis (Figure 1). 
medRxiv preprint doi: https://doi.org/10.1101/2021.11.29.21266847; this version posted November 30, 2021. The copyright holder for this preprint (which was not certified by peer review) is the author/funder, who has granted medRxiv a license to display the preprint in perpetuity.

It is made available under a CC-BY 4.0 International license .

Figure 1: Flow diagram of eligibility criteria for the evaluation of the CO@ programme

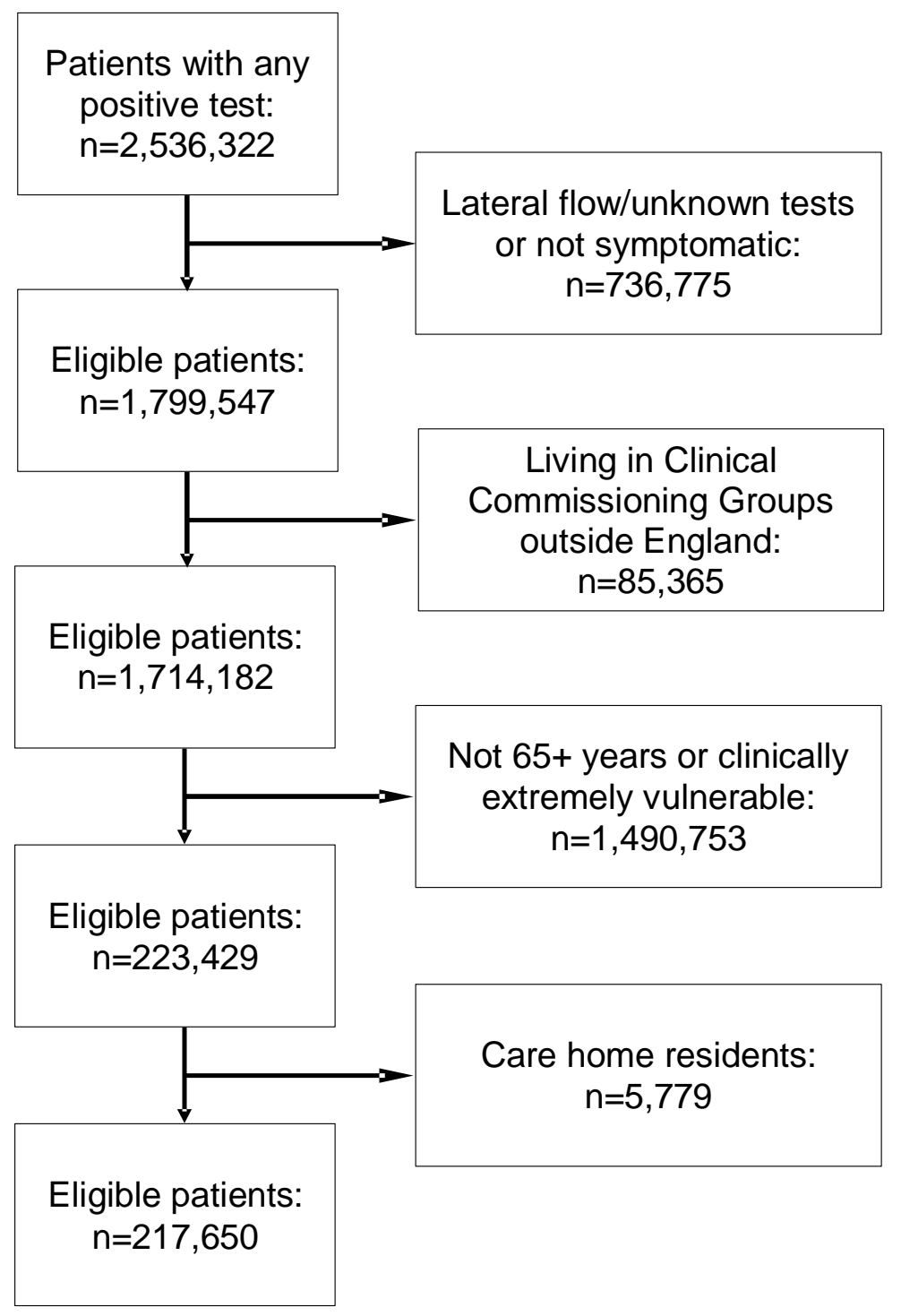


Most participants were women (54.4\%) and of White ethnic background (72.5\%), with $125,102(57.5 \%)$ in the five most deprived deciles. More of the population were obese (39.4\%) than overweight (33.6\%) or had a healthy weight (20.8\%). Just over half (54.9\%) were never smokers. Hypertension (40.6\%), diabetes (31.4\%; type 1 and type 2 ) and chronic respiratory disease $(29.3 \%)$ were the most common co-morbidities. A total of 5,616 $(2.6 \%)$ of the study population died within 28 days of a positive covid-19 test, $19.9 \%$ attended A\&E at least once, $12.2 \%$ were admitted at least once, and of those admitted, $16.1 \%$ required critical care. There were significant differences in distributions of most of the predictor and outcome variables in the eligible population before and after implementation in each site (Table 1).

Data was received via submissions from CO@h sites for 5,527 patients onboarded to the programme, giving an overall uptake rate based on submitted data of $2.5 \%$. There was considerable variation in uptake across CCGs, ranging from $0.0 \%$ to $33.0 \%$, with a median of $2.2 \%$ (Figure 2). The earliest date a site became operational was $20^{\text {th }}$ November 2020, with all sites operational from $10^{\text {th }}$ January 2021 . 
medRxiv preprint doi: https://doi.org/10.1101/2021.11.29.21266847; this version posted November 30, 2021. The copyright holder for this preprint (which was not certified by peer review) is the author/funder, who has granted medRxiv a license to display the preprint in perpetuity.

It is made available under a CC-BY 4.0 International license .

Table 1: Characteristics of people eligible for the $\mathrm{CO} @ \mathrm{~h}$ programme from 1 October 2020 to 3rd May 2021, before and after implementation at each site

\begin{tabular}{|c|c|c|c|c|c|}
\hline & \multicolumn{2}{|c|}{ Pre-implementation } & \multicolumn{2}{|c|}{ Post-implementation } & \multirow{2}{*}{$\begin{array}{l}\text { p-value for } \\
\text { difference }\end{array}$} \\
\hline & Number & Percentage & Number & Percentage & \\
\hline \multicolumn{6}{|c|}{ Age category (years) and Clinically Extremely Vulnerable status } \\
\hline 18-49 and CEV & 15364 & $20.5 \%$ & 33138 & $23.2 \%$ & \multirow{6}{*}{$\mathrm{p}<0.001$} \\
\hline 50-64 and CEV & 10319 & $13.8 \%$ & 21219 & $14.9 \%$ & \\
\hline 65-79 and not CEV & 36401 & $48.6 \%$ & 64181 & $45.0 \%$ & \\
\hline 65-79 and CEV & 5726 & $7.6 \%$ & 10010 & $7.0 \%$ & \\
\hline $80+$ and not CEV & 4875 & $6.5 \%$ & 9270 & $6.5 \%$ & \\
\hline $80+$ and CEV & 2215 & $3.0 \%$ & 4932 & $3.5 \%$ & \\
\hline \multicolumn{6}{|l|}{ Sex } \\
\hline Female & 39701 & $53.0 \%$ & 78610 & $55.1 \%$ & \multirow{3}{*}{$\mathrm{p}<0.001$} \\
\hline Male & 33896 & $45.3 \%$ & 61759 & $43.3 \%$ & \\
\hline Missing & 1303 & $1.7 \%$ & 2381 & $1.7 \%$ & \\
\hline \multicolumn{6}{|l|}{ Ethnicity } \\
\hline White & 58112 & $77.6 \%$ & 99703 & $69.8 \%$ & \multirow{6}{*}{$\mathrm{p}<0.001$} \\
\hline Asian/Asian British & 10725 & $14.3 \%$ & 25757 & $18.0 \%$ & \\
\hline Black/African/Caribbean/Black British & 1631 & $2.2 \%$ & 6755 & $4.7 \%$ & \\
\hline Mixed/Multiple ethnic groups & 685 & $0.9 \%$ & 1865 & $1.3 \%$ & \\
\hline Other ethnic group & 1076 & $1.4 \%$ & 3472 & $2.4 \%$ & \\
\hline Missing & 2671 & $3.6 \%$ & 5198 & $3.6 \%$ & \\
\hline \multicolumn{6}{|c|}{ Index of Multiple Deprivation (IMD) decile } \\
\hline 1 (most deprived) & 11697 & $15.6 \%$ & 16548 & $11.6 \%$ & \multirow{8}{*}{$\mathrm{p}<0.001$} \\
\hline 2 & 9207 & $12.3 \%$ & 18218 & $12.8 \%$ & \\
\hline 3 & 8038 & $10.7 \%$ & 17379 & $12.2 \%$ & \\
\hline 4 & 7233 & $9.7 \%$ & 15678 & $11.0 \%$ & \\
\hline 5 & 6884 & $9.2 \%$ & 14220 & $10.0 \%$ & \\
\hline 6 & 6510 & $8.7 \%$ & 13565 & $9.5 \%$ & \\
\hline 7 & 6691 & $8.9 \%$ & 12722 & $8.9 \%$ & \\
\hline 8 & 6839 & $9.1 \%$ & 12191 & $8.5 \%$ & \\
\hline
\end{tabular}


medRxiv preprint doi: https://doi.org/10.1101/2021.11.29.21266847; this version posted November 30, 2021. The copyright holder for this preprint (which was not certified by peer review) is the author/funder, who has granted medRxiv a license to display the preprint in perpetuity.

It is made available under a CC-BY 4.0 International license .

\begin{tabular}{|c|c|c|c|c|c|}
\hline 9 & 6380 & $8.5 \%$ & 11855 & $8.3 \%$ & \\
\hline 10 (least deprived) & 5409 & $7.2 \%$ & 10337 & $7.2 \%$ & \\
\hline Missing & 12 & $0.0 \%$ & 37 & $0.0 \%$ & \\
\hline \multicolumn{6}{|l|}{ Body Mass Index } \\
\hline Underweight & 724 & $1.0 \%$ & 1646 & $1.2 \%$ & \multirow{5}{*}{$p<0.001$} \\
\hline Healthy weight & 15181 & $20.3 \%$ & 29999 & $21.0 \%$ & \\
\hline Overweight & 25648 & $34.2 \%$ & 47591 & $33.3 \%$ & \\
\hline Obese & 29770 & $39.7 \%$ & 56064 & $39.3 \%$ & \\
\hline Missing & 3577 & $4.8 \%$ & 7450 & $5.2 \%$ & \\
\hline \multicolumn{6}{|l|}{ Smoking status } \\
\hline Never smoker & 39901 & $53.3 \%$ & 79530 & $55.7 \%$ & \multirow{4}{*}{$p<0.001$} \\
\hline Ex-smoker & 24770 & $33.1 \%$ & 41668 & $29.2 \%$ & \\
\hline Current smoker & 8862 & $11.8 \%$ & 18852 & $13.2 \%$ & \\
\hline Missing & 1367 & $1.8 \%$ & 2700 & $1.9 \%$ & \\
\hline \multicolumn{6}{|l|}{ Co-morbidities } \\
\hline Hypertension & 30548 & $40.8 \%$ & 57810 & $40.5 \%$ & 0.194 \\
\hline Chronic cardiac disease & 12482 & $16.7 \%$ & 22818 & $16.0 \%$ & $p<0.001$ \\
\hline Chronic kidney disease & 1070 & $1.4 \%$ & 2276 & $1.6 \%$ & 0.003 \\
\hline Chronic respiratory disease & 22514 & $30.1 \%$ & 41276 & $28.9 \%$ & $p<0.001$ \\
\hline Dementia & 790 & $1.1 \%$ & 1973 & $1.4 \%$ & $p<0.001$ \\
\hline Diabetes & 21558 & $28.8 \%$ & 46886 & $32.8 \%$ & $p<0.001$ \\
\hline $\begin{array}{l}\text { Chronic neurological disease } \\
\text { (including epilepsy) }\end{array}$ & 3004 & $4.0 \%$ & 6326 & $4.4 \%$ & $p<0.001$ \\
\hline Learning disability & 459 & $0.6 \%$ & 1037 & $0.7 \%$ & 0.002 \\
\hline Malignancy or immunosuppression & 15553 & $20.8 \%$ & 29204 & $20.5 \%$ & 0.092 \\
\hline Severe mental illness & 1358 & $1.8 \%$ & 3066 & $2.1 \%$ & $p<0.001$ \\
\hline Peripheral vascular disease & 1381 & $1.8 \%$ & 2264 & $1.6 \%$ & $\mathrm{p}<0.001$ \\
\hline Stroke or TIA & 3680 & $4.9 \%$ & 7154 & $5.0 \%$ & 0.316 \\
\hline Deaths within 28 days & 1476 & $2.0 \%$ & 4140 & $2.9 \%$ & $p<0.001$ \\
\hline $\begin{array}{l}\text { Patients with at least one ED } \\
\text { attendance within } 28 \text { days }\end{array}$ & 9965 & $13.3 \%$ & 24285 & $17.0 \%$ & $p<0.001$ \\
\hline
\end{tabular}


medRxiv preprint doi: https://doi.org/10.1101/2021.11.29.21266847; this version posted November 30, 2021. The copyright holder for this preprint (which was not certified by peer review) is the author/funder, who has granted medRxiv a license to display the preprint in perpetuity.

It is made available under a CC-BY 4.0 International license .

\begin{tabular}{|l|c|c|c|c|c|}
\hline $\begin{array}{l}\text { Patients with at least one emergency } \\
\text { admission within 28 days }\end{array}$ & 7539 & $10.1 \%$ & 18990 & $13.3 \%$ & $p<0.001$ \\
\hline Critical care use of those admitted & 1248 & $1.7 \%$ & 3027 & $2.1 \%$ & 0.220 \\
\hline Total & $\mathbf{7 4 9 0 0}$ & $\mathbf{3 4 . 4} \%$ & $\mathbf{1 4 2 7 5 0}$ & $\mathbf{6 5 . 6 \%}$ & \\
\hline
\end{tabular}

Figure 2: Percentage of the eligible population enrolled onto the $\mathrm{CO} @ \mathrm{~h}$ programme in each CCG from date of implementation based on submissions from sites
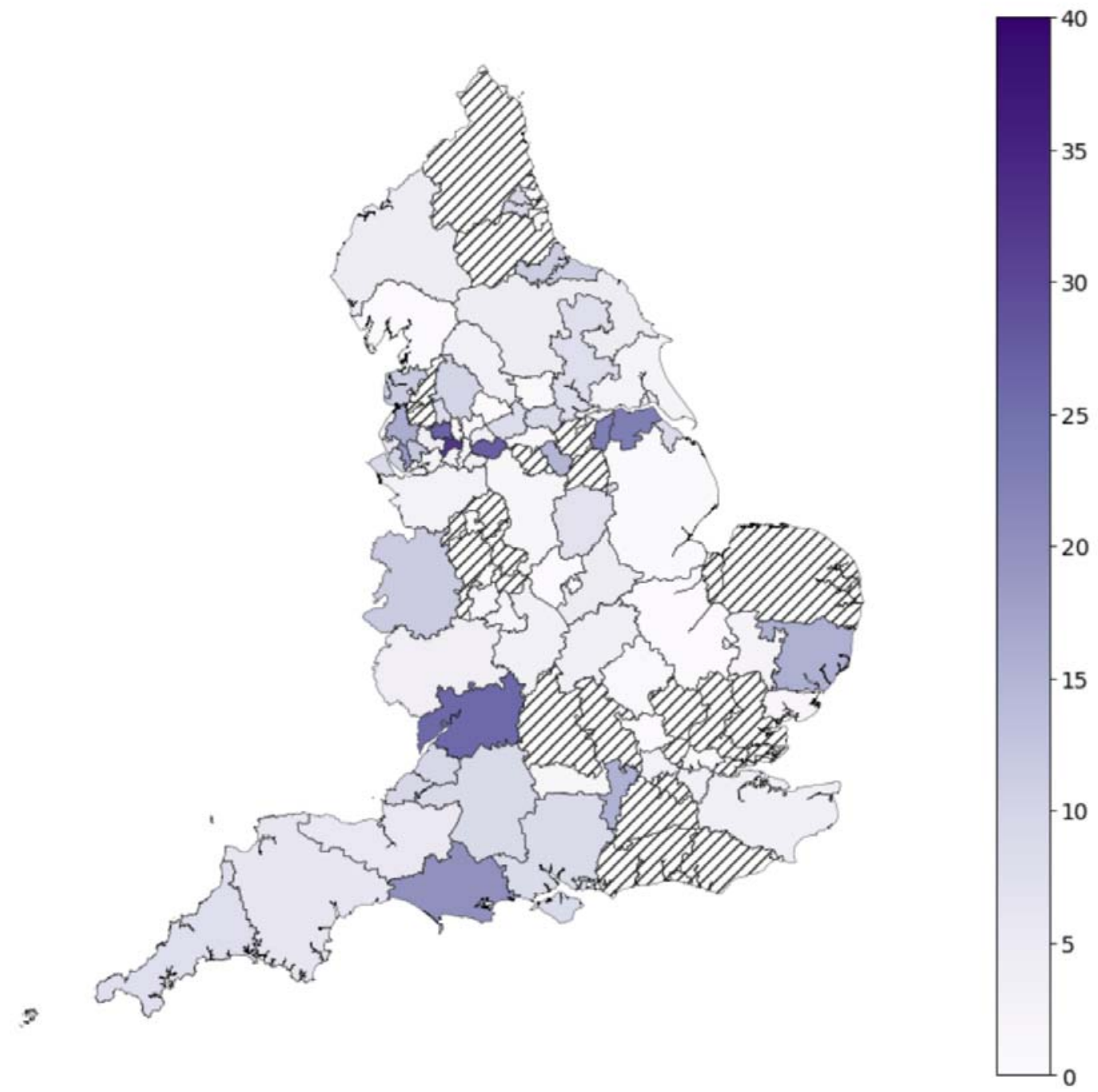

*Hashed areas represent CCGs with no patient onboarding data submitted 
Mixed effects logistic regression was run separately for each outcome, with CCG of residence as a random intercept. Table 2 shows the results for the primary analysis for each outcome, adjusted for month of covid-19 test and patient-level covariates. There was no significant difference in the adjusted odds of 28-day mortality following implementation of the $\mathrm{CO} @ \mathrm{~h}$ programme $(\mathrm{aOR}=1.06, \mathrm{p}=0.405)$. There was evidence of a small increase in both $\mathrm{A} \& \mathrm{E}$ attendances $(\mathrm{aOR}=1.12, \mathrm{p}<0.001)$ and emergency hospital admissions $(\mathrm{aOR}=1.12$, $\mathrm{p}<0.001)$ within 28 days. Of those patients admitted to hospital after implementation there was a $24 \%$ increase in the adjusted odds of requiring critical care (aOR 1.24, $\mathrm{p}=0.012$ ). There was no significant difference in the length of stay of those admitted $(\mathrm{p}=0.588)$.

Table 2: Effect measures for the CO@h programme, from mixed effects regression models, adjusted for month of test and patient-level covariates

\begin{tabular}{|c|c|c|c|c|c|c|}
\hline \multirow{2}{*}{ Outcome } & \multirow{2}{*}{$\begin{array}{l}\text { Adjusted odds } \\
\text { ratio }\end{array}$} & \multirow{2}{*}{$\begin{array}{l}\text { Standard } \\
\text { error }\end{array}$} & \multirow{2}{*}{$\begin{array}{c}\mathrm{p}- \\
\text { value }\end{array}$} & \multicolumn{2}{|c|}{$\begin{array}{l}95 \% \text { confidence } \\
\text { interval }\end{array}$} & \multirow{2}{*}{ Denominator } \\
\hline & & & & Lower & Upper & \\
\hline 28-day mortality & 1.06 & 0.072 & 0.405 & 0.93 & 1.21 & 203,218 \\
\hline $\begin{array}{l}\text { Any } A \& E \text { attendance } \\
\text { within } 28 \text { days }\end{array}$ & 1.12 & 0.033 & $<0.001$ & 1.06 & 1.18 & 203,218 \\
\hline $\begin{array}{l}\text { Any hospital admission } \\
\text { within } 28 \text { days }\end{array}$ & 1.12 & 0.037 & $<0.001$ & 1.05 & 1.20 & 203,218 \\
\hline \multirow[t]{2}{*}{$\begin{array}{l}\text { Critical care use of those } \\
\text { admitted }\end{array}$} & 1.24 & 0.107 & 0.012 & 1.05 & 1.47 & 24,895 \\
\hline & $\begin{array}{l}\text { Adjusted } \\
\text { IRR }^{\star}\end{array}$ & $\begin{array}{l}\text { Standard } \\
\text { error }\end{array}$ & $\begin{array}{c}p- \\
\text { value }\end{array}$ & Lower & Upper & Denominator \\
\hline $\begin{array}{l}\text { Length of stay of those } \\
\text { admitted (in days) }\end{array}$ & 1.02 & 0.029 & 0.588 & 0.96 & 1.07 & 20,794 \\
\hline
\end{tabular}

*IRR = Incidence Rate Ratio from negative binomial regression 


\section{Sensitivity analyses}

Sensitivity analyses comparing alternative model specifications are given in the Appendix (Tables A1-5). Naïve models, unadjusted for time, showed significant increases in 28-day mortality, ED attendance and admissions associated with the programme. In contrast, in naïve models, the programme was weakly associated with lower odds of critical care admission. Little meaningful difference was seen in the estimates between models unadjusted or adjusted for patient-level covariates, or with the addition of random time by CCG interactions. The intraclass coefficients for both CCG and CCG by time interactions for mortality, ED attendance and hospital admission models were all $<1 \%$, suggesting minimal variation between CCGs that might be accounted for by time-varying CCG level factors.

\section{Secondary analysis of high uptake CCGs}

Two secondary analyses using the same stepped wedge designed were performed for sixteen CCGs with $10 \%$ or more uptake (Table 4), and for five CCGs with $20 \%$ or more uptake (Table 5). In the $10 \%$ uptake group, there was a $9 \%$ lower odds or mortality, $10 \%$ higher odds of A\&E attendance and 23\% higher odds of critical care admission after implementation, but all effects were statistically non-significant. There was evidence of $27 \%$ higher odds of admission ( $\mathrm{p}=0.046$ ). In the $20 \%$ uptake CCGs, effect sizes were larger, but none were statistically significant. 
Table 3: Effect measures for $\mathrm{CO} @ \mathrm{~h}$ sites with $10 \%$ or more uptake, from mixed effects logistic/negative binomial regression models, adjusted for month of test and patientlevel factors

\begin{tabular}{|c|c|c|c|c|c|c|}
\hline \multirow{2}{*}{ Outcome } & \multirow{2}{*}{$\begin{array}{l}\text { Adjusted odds } \\
\text { ratio }\end{array}$} & \multirow{2}{*}{$\begin{array}{l}\text { Standard } \\
\text { error }\end{array}$} & \multirow{2}{*}{$\begin{array}{c}p- \\
\text { value }\end{array}$} & \multicolumn{2}{|c|}{$\begin{array}{l}95 \% \text { confidence } \\
\text { interval }\end{array}$} & \multirow{2}{*}{ Denominator } \\
\hline & & & & Lower & Upper & \\
\hline 28-day mortality & 0.91 & 0.225 & 0.715 & 0.56 & 1.48 & 19,724 \\
\hline $\begin{array}{l}\text { Any } A \& E \text { attendance } \\
\text { within } 28 \text { days }\end{array}$ & 1.10 & 0.120 & 0.369 & 0.89 & 1.37 & 19,724 \\
\hline $\begin{array}{l}\text { Any hospital admission } \\
\text { within } 28 \text { days }\end{array}$ & 1.27 & 0.151 & 0.046 & 1.00 & 1.60 & 19,724 \\
\hline \multirow[t]{2}{*}{$\begin{array}{l}\text { Critical care use of those } \\
\text { admitted }\end{array}$} & 1.23 & 0.373 & 0.496 & 0.68 & 2.23 & 2,608 \\
\hline & $\begin{array}{l}\text { Adjusted } \\
\text { IRR* }^{*}\end{array}$ & $\begin{array}{l}\text { Standard } \\
\text { error }\end{array}$ & $\begin{array}{c}p- \\
\text { value }\end{array}$ & Lower & Upper & Denominator \\
\hline $\begin{array}{l}\text { Length of stay (days) of } \\
\text { those admitted }\end{array}$ & 1.13 & 0.112 & 0.213 & 0.93 & 1.37 & 2,171 \\
\hline
\end{tabular}

*IRR = Incidence Rate Ratio

Table 4: Effect measures for CO@h sites with $20 \%$ or more uptake, from mixed effects logistic/negative binomial regression models, adjusted for month of test and patientlevel factors

\begin{tabular}{|c|c|c|c|c|c|c|}
\hline \multirow{2}{*}{ Outcome } & \multirow{2}{*}{$\begin{array}{l}\text { Adjusted odds } \\
\text { ratio }\end{array}$} & \multirow{2}{*}{$\begin{array}{l}\text { Standard } \\
\text { error }\end{array}$} & \multirow{2}{*}{$\begin{array}{c}\mathrm{p}- \\
\text { value }\end{array}$} & \multicolumn{2}{|c|}{$\begin{array}{l}95 \% \text { confidence } \\
\text { interval }\end{array}$} & \multirow{2}{*}{ Denominator } \\
\hline & & & & Lower & Upper & \\
\hline 28-day mortality & 0.89 & 0.397 & 0.798 & 0.37 & 2.13 & $4,807 \dagger$ \\
\hline $\begin{array}{l}\text { Any A\&E attendance } \\
\text { within } 28 \text { days }\end{array}$ & 1.27 & 0.248 & 0.216 & 0.87 & 1.86 & 4,887 \\
\hline $\begin{array}{l}\text { Any hospital admission } \\
\text { within } 28 \text { days }\end{array}$ & 1.44 & 0.317 & 0.102 & 0.93 & 2.21 & 4,887 \\
\hline \multirow[t]{2}{*}{$\begin{array}{l}\text { Critical care use of those } \\
\text { admitted }\end{array}$} & 1.64 & 0.954 & 0.393 & 0.53 & 5.13 & 652 \\
\hline & $\begin{array}{l}\text { Adjusted } \\
\text { IRR }^{\star}\end{array}$ & $\begin{array}{l}\text { Standard } \\
\text { error }\end{array}$ & $\begin{array}{c}p- \\
\text { value }\end{array}$ & Lower & Upper & Denominator \\
\hline $\begin{array}{l}\text { Length of stay (days) of } \\
\text { those admitted }\end{array}$ & 1.27 & 0.259 & 0.246 & 0.85 & 1.89 & 552 \\
\hline
\end{tabular}

*IRR = Incidence Rate Ratio. $\quad$ †80 observations excluded in April/May as no deaths occurring 


\section{Discussion}

At a population level, there was no impact on mortality after implementation of the $\mathrm{CO} @ \mathrm{~h}$ programme. Implementation was associated with statistically significant increases in A\&E attendances and emergency hospital admissions, with a $12 \%$ increase in the odds of both $A \& E$ attendance or admission within 28 days of a positive test. There was some evidence of an increase in the odds of receiving critical care in patients admitted after implementation of the CO@ $\mathrm{h}$ programme. In a secondary analysis of sites with at least $10 \%$ or at least $20 \%$ of eligible people onboarded, there was a trend towards lower odds of death and higher odds of A\&E attendance, hospital admission and critical care after implementation, but effects were non-significant.

Increases in A\&E attendances, emergency hospital admissions and critical care use following implementation of CO@ h may reflect early recognition of silent hypoxia in covid-19. The magnitude of increase in $A \& E$ attendances was similar to the magnitude of increase in hospital admissions, suggesting that implementation did not cause a large increase in A\&E attendances not requiring admission. However, early intervention might be expected to decrease length of stay and mortality, which was not found here. Despite this, the finding of no significant difference in mortality after implementation suggests that the CO@h pathway is safe and does not cause harm. Uptake of the programme was lower than expected, with data received from only $2.5 \%$ of the eligible population. This may be due to incomplete data submissions or may reflect genuinely low uptake of the programme. It could also reflect additional patient selection criteria used by sites, for example, if sites were focussing on patients with higher acuity disease. If uptake were only $2.5 \%$, then there is likely to be a dilutional effect when evaluating results at a population level and we cannot infer a causal relationship at an individual level.

Remote monitoring technologies have been widely used in the management chronic diseases, but with mixed evidence of their clinical effectiveness[18] and there is limited evidence for their use in covid-19 with which to compare our findings (Alboksmaty, A et al. Effectiveness and safety of pulse oximetry in remote home monitoring of COVID-19 patients: a systematic review. Unpublished, under review at The Lancet Digital Health). A previous pilot study of four NHS covid-19 pulse oximetry programmes in England indicated the pathway was safe, but did not include a control group to compare outcomes.[19] A study in the US of patients with covid-19 referred to a remote patient monitoring pathway after discharge from hospital 
found lower odds of emergency department or hospital reattendance in those enrolled, but did not assess mortality.[20] Furthermore, the characteristics of patients discharged from hospital with covid-19 may be different to people in the community eligible for $\mathrm{CO} @ \mathrm{~h}$, who are likely to be at an earlier stage of disease.

In a separate study of $\mathrm{CO} @ \mathrm{~h}$ programme by the same authors using a retrospective matched cohort design, patients with covid-19 enrolled after assessment in A\&E were found to have lower odds of mortality and critical care use, and higher odds of subsequent A\&E use and admission, compared with matched controls.[21] Collectively, results from the two studies suggest that although there was no impact on mortality at a population level, there is evidence for the effectiveness of the programme at an individual level (albeit within a narrower eligibility cohort of patients assessed in $A \& E$ ), but indicate that the programme could not be scaled up to provide a benefit to all eligible people nationally. Crucially, neither of the studies indicate a concern over the clinical safety of the programme or that it causes harm. There is a need for further research into the barriers and facilitators to implementation of the programme and the obstacles to wider adoption which may aid policy-makers and commissioners in implementing remote monitoring programmes in the future. There is also a need to understand the equity of access to $\mathrm{CO} @ \mathrm{~h}$, and whether low enrolment nationally is reflected in lower numbers onboarded in certain sociodemographic groups, and to evaluate user experience and the cost implications of the programme.

\section{Strengths and limitations}

A strength of this study is the availability of comprehensive data on covid-19 testing, defining a robust denominator population. Through linkage to primary and secondary care records, we identified the eligible population and adjusted for underlying risk factors differing between the population pre- and post-implementation. Eligibility for the programme was not absolute, with NHS England recommending an extended age threshold of 50 years and over from February 2021. Our analysis focussed on a narrower subgroup of people aged 65 or over or CEV, who would have remained eligible over the full study period, but as a result, findings might not be generalisable to all those included in the programme.

The stepped wedge design was chosen in part as it is robust to biases in decisions regarding onboarding of patients (such as systematic onboarding of higher or lower risk patients), 
which would impact individual level study designs. The effect estimates are also not impacted by lack of submission of patient-level programme data on patients onboarded, which may not be complete. However, incompleteness of received data does impact on our ability to judge the degree to which the study was adequately powered to detect a difference in mortality should one exist. The primary analysis adjusted for patient covariates, for which data were incomplete. However, the impact on the estimates is unlikely to be significant, as sensitivity analyses adjusted for patient-level covariates produced very similar estimates to the primary analysis.

Results may also be confounded by events external to the programme. A separate study using the same data sources showed significant increases in the case hospitalisation and fatality risk from covid-19 from October 2020 to January 2021 at the time CO@ h sites were becoming operational.[22] These trends may relate to winter effects on mortality, new treatments, hospital pressures and spread of the alpha variant which became the dominant covid-19 strain in England during December 2020.[23,24] Despite the stepped wedge analysis incorporating time as an adjusting covariate, there may be residual confounding between sites becoming operational, and the underlying increase in mortality rates, particularly given the low numbers onboarded. Incorporation of additional CCG-level and hospital-level covariates was considered but estimates of the residual variation explained by clustering at the CCG-level (intra-class correlation coefficient) were less than $1 \%$, suggesting these would have limited impact. The primary analysis considered time-varying CCG level effects in additional sensitivity analyses for each outcome, with almost identical effect measures compared to the primary analysis, suggesting little impact of time-varying differences between CCGs.

Across England, CO@h sites implemented different types of model, run by different sectors of the healthcare system, and with different recommendations for the frequency of monitoring.[4] National population effect estimates as presented here may therefore mask variation in the effectiveness between programmes and so not be representative of individual sites. Our analysis incorporated outcomes measured up to 28 days from the date of a positive covid-19 test, and different effects may be seen over longer time periods. Longer term outcomes, such as 'Long Covid' might also be affected by early recognition of low oxygen saturations but were outside of the scope of this study.

\section{Conclusion}


Implementation of the CO@h programme across England had no impact on mortality at a population level and was associated with small increases in A\&E attendances, hospitalisations and critical care use in people with covid-19 aged 65 years or over or CEV, which may indicate early recognition of hypoxia and escalation. Lower than expected enrolment of eligible people may have diluted the effects of the programme at a population level. There is a need for further research into the uptake and effectiveness of remote monitoring programmes for covid-19.

\section{Acknowledgements}

The authors would like to thank Hutan Ashrafian, Gianluca Fontana, Saira Ghafur, Melanie Leis and Mahsa Mazidi for their input and support. Data management was provided by the Big Data and Analytical Unit (BDAU) at the Institute of Global Health Innovation (IGHI), Imperial College London. This work was funded by NHS England and supported by the National Institute for Health Research (NIHR) Imperial Patient Safety Translation Research Centre. Infrastructure support was provided by the NIHR Imperial Biomedical Research Centre (BRC). JC acknowledges support from the Wellcome Trust (215938/Z/19/Z).

\section{Data availability statement}

The patient level data used in this study are not publicly available but are available to applicants meeting certain criteria through application of a Data Access Request Service (DARS) and approval from the Independent Group Advising on the Release of Data.

\section{Ethics approval}

The work was conducted as a national service evaluation of the $\mathrm{CO} @ \mathrm{~h}$ programme, approved by Imperial College Health Trust on $3^{\text {rd }}$ December 2020. Data access was approved by the Independent Group Advising on the Release of Data (IGARD; DARS-NIC-421524-R0Y3P) on $15^{\text {th }}$ April 2021. 


\section{References}

1 Greenhalgh T, Knight M, Inada-Kim M, et al. Remote management of covid-19 using home pulse oximetry and virtual ward support. BMJ 2021;372. doi:10.1136/bmj.n677

2 Levitan RM. Pulse Oximetry as a Biomarker for Early Identification and Hospitalization of COVID-19 Pneumonia. Acad. Emerg. Med. 2020;27:785-6. doi:10.1111/acem.14052

3 Jouffroy R, Jost D, Prunet B. Prehospital pulse oximetry: a red flag for early detection of silent hypoxemia in COVID-19 patients. Crit Care 2020;24:313. doi:10.1186/s13054-020-03036-9

4 Vindrola-Padros C, Sidhu MS, Georghiou T, et al. The implementation of remote home monitoring models during the COVID-19 pandemic in England.

EClinicalMedicine 2021;34:100799. doi:10.1016/j.eclinm.2021.100799

5 Clarke J, Flott K, Crespo RF, et al. Assessing the safety of home oximetry for COVID19: a multisite retrospective observational study. BMJ Open 2021;11:e049235. doi:10.1136/BMJOPEN-2021-049235

6 Coronavirus $\square \gg$ Pulse oximetry to detect early deterioration of patients with COVID19 in primary and community care settings.

7 NHS Digital. Coronavirus $\square »$ Novel coronavirus (COVID-19) standard operating procedure: COVID Oximetry @ home.

$8 \quad$ NHS Digital. Shielded Patient List Risk Criteria. 2021.https://digital.nhs.uk/coronavirus/shielded-patient-list/risk-criteria (accessed 22 Sep 2021).

$9 \quad$ NHS England $\square \gg$ COVID virtual wards.

10 Graham NSN, Junghans C, Downes R, et al. SARS-CoV-2 infection, clinical features and outcome of COVID-19 in United Kingdom nursing homes. J Infect Published Online First: 2020. doi:https://doi.org/10.1016/j.jinf.2020.05.073

11 Public Health England. Laboratory reporting to Public Health England: A guide for diagnostic laboratories. 2020.

12 Department of Health \& Social Care. COVID-19 testing data: methodology note. 2021.https://www.gov.uk/government/publications/coronavirus-covid-19-testing-datamethodology/covid-19-testing-data-methodology-note (accessed 6 Oct 2021).

13 NHS Digital. Strategic Data Collection Service (SDCS). https://digital.nhs.uk/services/strategic-data-collection-service-sdcs (accessed 6 Oct 2021). 
14 NHS Digital. General Practice Extraction Service (GPES) Data for pandemic planning and research: a guide for analysts and users of the data.

2021.https://digital.nhs.uk/coronavirus/gpes-data-for-pandemic-planning-andresearch/guide-for-analysts-and-users-of-the-data (accessed 30 Sep 2021).

15 Digital N. Hospital Episode Statistics (HES). https://digital.nhs.uk/data-andinformation/data-tools-and-services/data-services/hospital-episode-statistics (accessed 6 Oct 2021).

16 NHS Digital. Emergency Care Data Set (ECDS). https://digital.nhs.uk/data-andinformation/data-collections-and-data-sets/data-sets/emergency-care-data-set-ecds (accessed 6 Oct 2021).

17 Ministry of Housing, Communities \& Local Government. English indices of deprivation 2019. https://www.gov.uk/government/statistics/english-indices-ofdeprivation-2019 (accessed 18 Oct 2020).

18 Noah B, Keller MS, Mosadeghi S, et al. Impact of remote patient monitoring on clinical outcomes: an updated meta-analysis of randomized controlled trials. npj Digit Med 2018;1:20172. doi:10.1038/s41746-017-0002-4

19 Clarke J, Flott K, Fernandez Crespo R, et al. Assessing the safety of home oximetry for COVID-19: a multisite retrospective observational study. BMJ Open 2021;11. doi:10.1136/bmjopen-2021-049235

20 Gordon WJ, Henderson D, DeSharone A, et al. Remote Patient Monitoring Program for Hospital Discharged COVID-19 Patients. Appl Clin Inf 2020;11:792-801.

21 Beaney T, Clarke J, Alboksmaty A, et al. Evaluating the impact of a pulse oximetry remote monitoring programme on mortality and healthcare utilisation in patients with covid-19 assessed in Accident and Emergency departments in England: a retrospective matched cohort study. medRxiv 2021.

22 Beaney T, Neves AL, Alboksmaty A, et al. Trends and associated factors for Covid-19 hospitalisation and fatality risk in 2.3 million adults in England. medRxiv 2021.

23 Office for National Statistics. Excess winter mortality in England and Wales: 2019 to 2020 (provisional) and 2018 to 2019 (final). 2020.

https://www.ons.gov.uk/peoplepopulationandcommunity/birthsdeathsandmarriages/de aths/bulletins/excesswintermortalityinenglandandwales/2019to2020provisionaland201 8to2019final

24 Challen R, Brooks-Pollock E, Read JM, et al. Risk of mortality in patients infected with SARS-CoV-2 variant of concern 202012/1: matched cohort study. BMJ 
medRxiv preprint doi: https://doi.org/10.1101/2021.11.29.21266847; this version posted November 30, 2021. The copyright holder for this preprint (which was not certified by peer review) is the author/funder, who has granted medRxiv a license to display the preprint in perpetuity. It is made available under a CC-BY 4.0 International license .

2021;372. doi:10.1136/bmj.n579 